\title{
Duas ou três ideias sobre um teatro necessário As Comédias do Minho
} Alexandra Moreira da Silva

\section{A movida artística}

Num pequeno texto de introdução ao programa de 2011 das Comédias do Minho, o leitor / espetador contemporâneo, incauto porque conformado com a já habitual necessidade de circunscrever o seu interesse ao que se vai fazendo aqui e agora, adiando a sua natural curiosidade relativamente a configurações programáticas mais amplas - entenda-se para uma temporada - sendo obrigado a resignar-se, não raras vezes, perante a incerteza ou, pior ainda, o abandono de projetos e ambições nas mais variadas áreas e domínios artísticos, espanta-se com a ousadia, o otimismo, a confiança e a persistência que podemos ler nas palavras inaugurais do referido texto: "As Comédias do Minho, durante os próximos dois anos, vão mergulhar ainda mais no seu Território à procura de novos desafios - temas e paisagens do Vale do Minho vão ser ponto forte de arriscados e profundos trabalhos de criação". 0 mais extraordinário é que prometeram e cumpriram. Pelo menos no primeiro ano, em 2011, e, de acordo com o novo caderno de programação, preparamse já para assegurar o segundo ano com o mesmo dinamismo e a mesma criatividade.

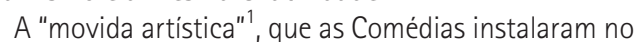
Alto Minho, passa muito pela Companhia de Teatro da qual fazem parte, para além do seu diretor artístico João Pedro Vaz, os actores e criadores Gonçalo Fonseca, Luís Filipe Silva, Mónica Tavares, Rui Mendonça e Tânia Almeida, que decidiram mudar-se com diferentes armas artísticas e reconhecida bagagem teatral para o Alto Minho, dispostos a arregaçarem as mangas e a dedicarem-se, talvez mais do que nunca, a essa "arte poderosamente arcaica", como Ihe chama Jean-Christophe Bailly (2006: 67), que é o teatro. Mas não só dos residentes vive a dinâmica deste projeto. A "movida" implica, desde logo, uma rede de vasos comunicantes que tem levado até aos cinco concelhos do Vale do Minho (Melgaço, Monção, Paredes de Coura,
Valença e Vila Nova de Cerveira) criadores tão diversos quanto Pedro Penim, Madalena Vitorino, Sílvia Real, Igor Gandra, Marcos Barbosa ou mais recentemente Nuno Cardoso e Joana Providência. Escusado será dizer que não se trata de fazer um teatro regionalista, nem sequer um teatro etnográfico. Os projetos partem de materiais e ferramentas que funcionam "em Melgaço ou em Reiquejavique" 2 como afirma Pedro Penim: de Steven Berkoff, aos vídeos do YouTube, passando pela Bíblia ou pelo Fidalgo aprendiz, tudo pode ser trabalhado, repensado e visto no Alto Minho, com o mesmo rigor e a mesma seriedade com que estes trabalhos foram apresentados no Balleteatro, no Porto, ou no TNDMII, em Lisboa.

Em 2011, permito-me destacar o projeto Casa grande, co-produzido pela Fundação Lapa do Lobo, que resultou na criação de cinco espetáculos a partir de cinco espaços físicos diferentes. Casas de familia, solares desabitados, vazios ou devolutos, foram ocupados, transformados, revisitados por Tânia Almeida, que assinou a encenação deste projeto, por atores (profissionais e amadores), por Rui Mendonça, Lucilia Raimundo, Ana Limpinho, Maria João Castelo e Vasco Ferreira que integraram a equipa artística de Casa grande, e sobretudo por um público atento, ávido e de uma rara heterogeneidade, todos convictos e conscientes de que os espaços também têm memória. E com a memória vem o tempo, e com o tempo vêm as histórias (da aristocracia monárquica na passagem para a República, por exemplo, ou dos militantes antifascistas na clandestinidade no periodo pré-revolucionário). Em 1983, numa conferência proferida em Roma, Antoine Vitez fazia a seguinte afirmação sobre a prática teatral:

É um trabalho de ordem monástica, mesmo se a nossa vida não é monástica. Somos pessoas que nos fechamos em sítios fechados [...] e nesses lugares conservamos frases que já foram pronunciadas e concebidas, e dedicamo-nos a

\section{A expressão "movida \\ artistica" surge no final do texto de introduç̃o ao programa de 2011 das Comédias do Minho: "Um programa intenso, utópico, enérgico! Contra a austeridade, uma verdadeira movida artistica, um centro cultural itinerante, um centro cultural na} paisagem!"

${ }^{2}$ Pedro Penim citado por Inês Nadais in "Reiquejavique no Alto Minho", Público, 06.01.2009.

Alexandra Moreira da Silva é Professora da Faculdade de Letras da Universidade do Porto e investigadora do Instituto de Literatura Comparada Margarida Losa da mesma universidade. É tradutora e dramaturgista, e foi distinguida em 2011 pelo governo francês com titulo de Chevalier dans l'ordre des Palmes Académiques. 
Oesmagador de uvas,

enc. John Mowat

Comédias do Minho,

2012 (Luis Filipe Silva) fot. Celeste Domingues.

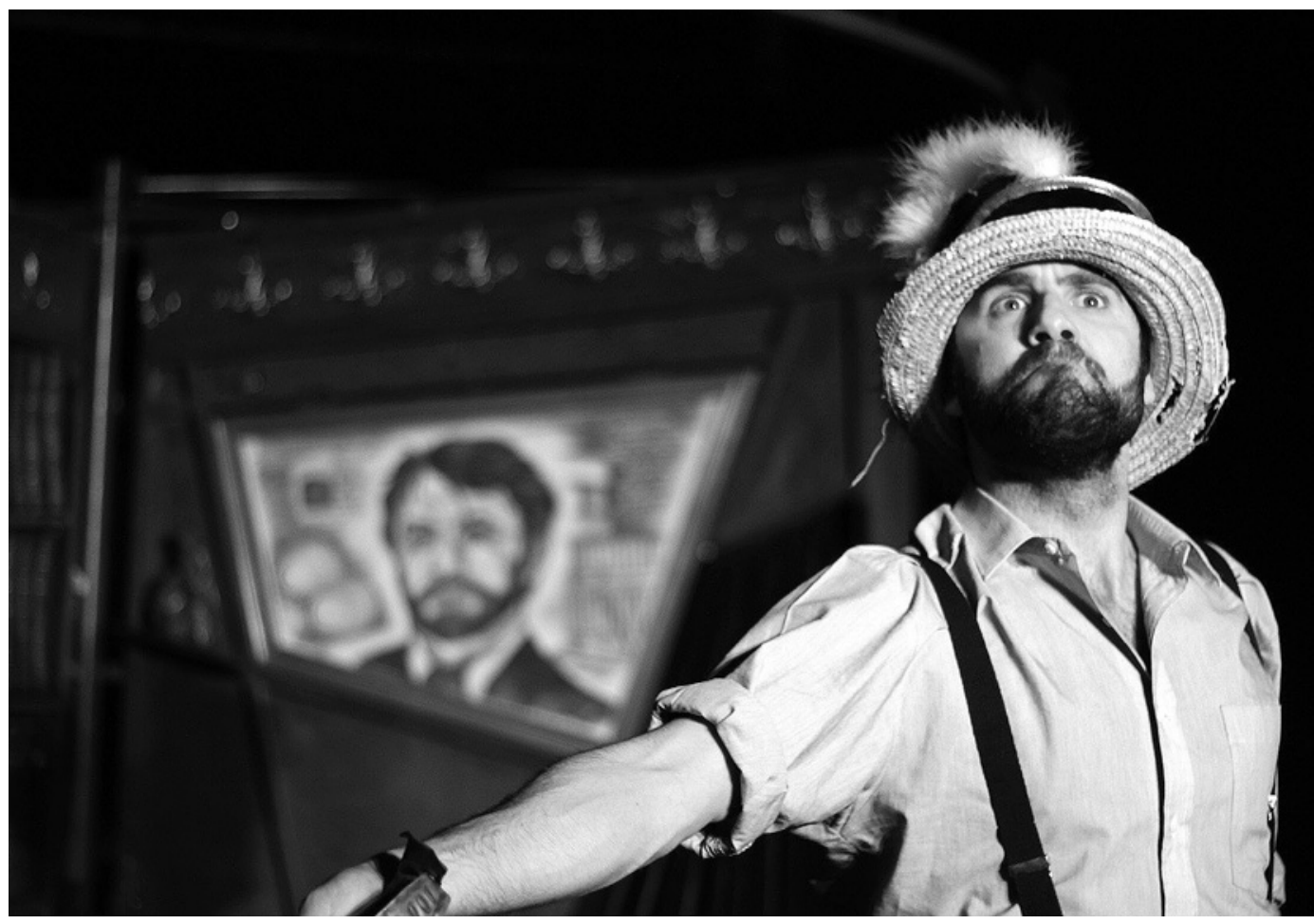

Péde vento

criação: Margarida Mestre e Mónica Tavares

Comédias do Minho, 2010

(Mónica Tavares), fot. Susana Neves.

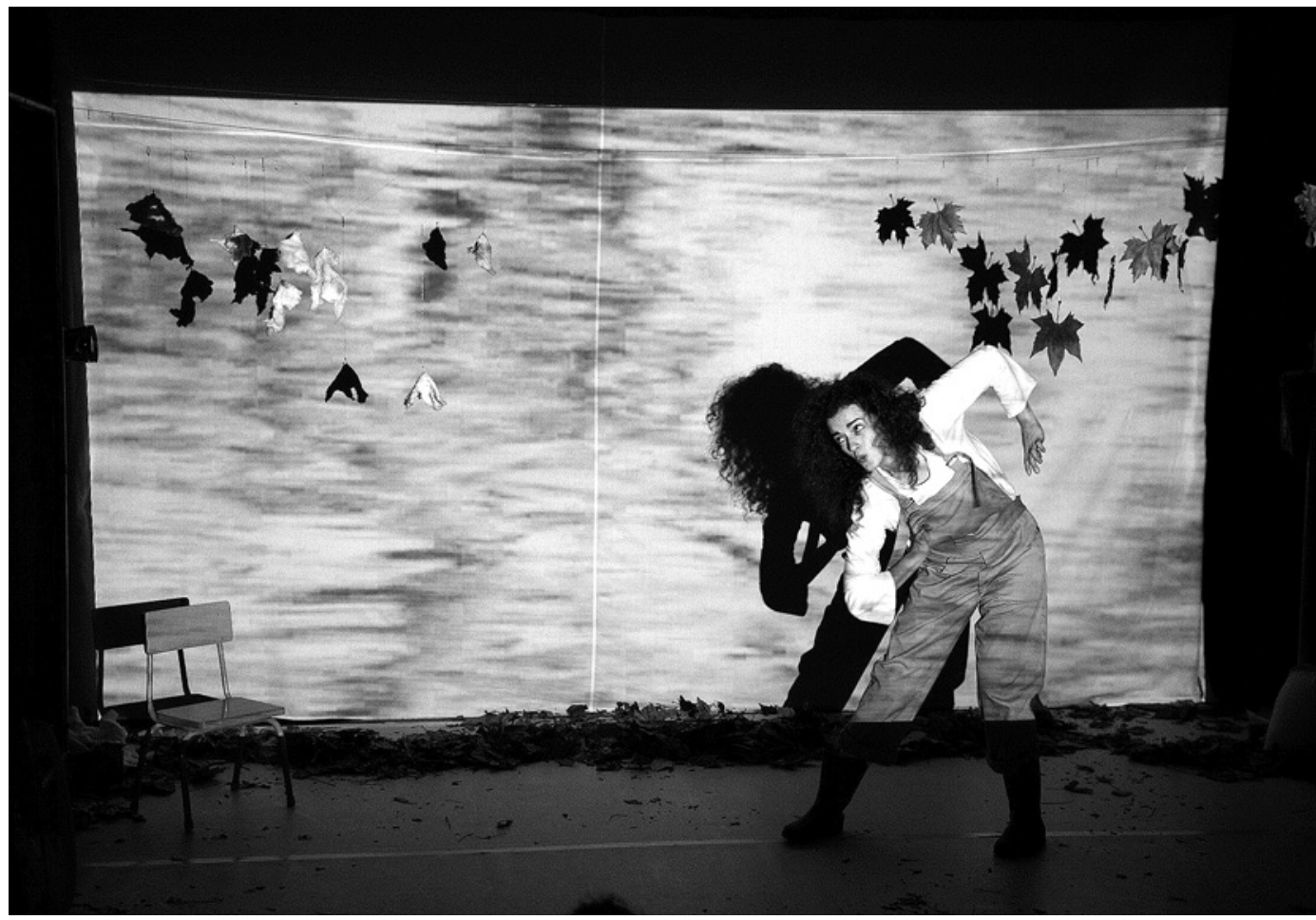

reconstituir movimentos através da imaginação e a partir do rasto de acções que foram escritas. Fazemos isto para trabalhar para criticar a memória da humanidade. É este o nosso ofício trabalhar sobre esta memória. (2006: 108, trad. minha)

Entre o íntimo e o político, Casa grande parece subscrever as palavras de Antoine Vitez, apresentandose, antes de mais, como um projeto que interroga a identidade, que percorre insistentemente um espaço, um tempo, uma memória, e que deste modo questiona e reescreve a ficção.
2. “Aproximarte" é aproximarmo-nos: itinerâncias polifónicas

Entre a criação contemporânea e o trabalho no terreno as Comédias não têm tempo a perder. 0 projeto

"Aproximarte" envolve várias escolas dos cinco concelhos do Vale do Minho do ensino pré-escolar, básico e secundário, bem como professores, familias e utentes APPACDM (Associação Portuguesa de Pais e Amigos do Cidadão Deficiente Mental). Contrariamente ao que se possa imaginar, esta vertente pedagógica das Comédias não constitui uma atividade marginal, bem pelo contrário, 


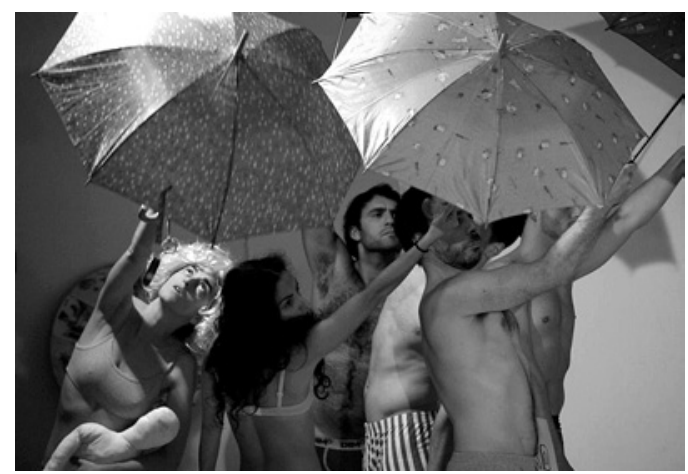

Inverno

enc. Nuno Cardoso,

Comédias do Minho

e Ao Cabo Teatro, 2011

(Mónica Tavares,

Tânia Almeida,

Luis Filipe Silva

e João Melo),

fot. Celeste Domingues.

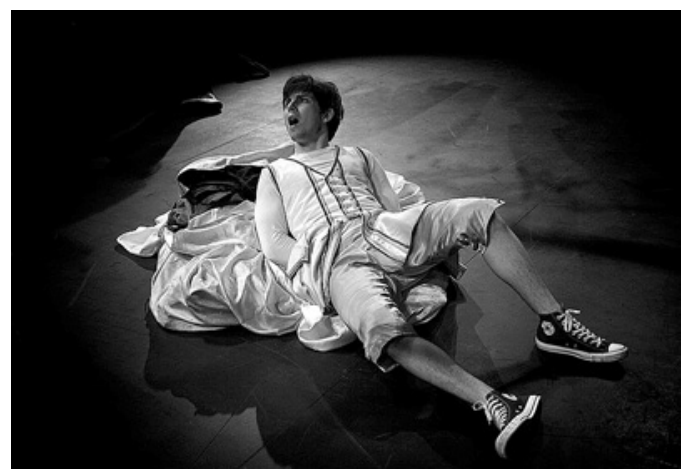

trata-se de um labor nuclear que escolhe e utiliza uma grande diversidade de ferramentas e de estratégias: oficinas de dança, de cinema de animação, de movimento, de formação artística, cursos de teatro, encontros com criadores... são apenas algumas das propostas que visam a promoção e o desenvolvimento de um conceito de "público" que conscientemente contraria a muito contemporânea noção de "audiência". Isabel Alves Costa, mentora incontornável deste projeto, falava da necessidade de se estabelecer "uma relação íntima com a população": "Aqui vemos ao vivo o que é a formação dos públicos", afirma. "A atitude das pessoas é: mas o que é que eles irão fazer a seguir? Não estão de todo à espera do mesmo" ${ }^{3}$, conclui. Mas estão à espera de alguma coisa. Esperam verdadeiramente, e isso será talvez o que de mais político existe no teatro. Como afirma Denis Guénoun "o caráter político do teatro não está no palco - ou [...] em todo o caso, não é no palco que ele se encontra em primeiro lugar - mas sim na sala" (2009: 46). Ou seja, nessa capacidade de conseguir reunir, a uma certa hora, num determinado lugar, uma comunidade a que talvez possamos chamar "teatral". Em 2011, 13.500 espetadores assistiram aos espetáculos das Comédias do Minho número invejável nos tempos que correm.

Contudo, mais importante do que os números - e este é certamente um dos grandes méritos das Comédias - será esta vontade, esta capacidade de criar aquilo a que Jean-Christophe Bailly chama "uma comunidade de espera", conceito a distinguir de uma pura aproximação quantitativa porque, como refere o autor, "não é adicionando o número de leitores de livros, o número de visitantes de exposições e o número de espetadores de teatro que assistiremos à formação de uma qualquer consistência" (2006: 77). A "comunidade de espera" pressupõe uma vontade de abertura. Abertura ao tempo, desde logo, a um tempo lento que mais não é do que um espaço de sentidos e de desejo de partilha desses sentidos.

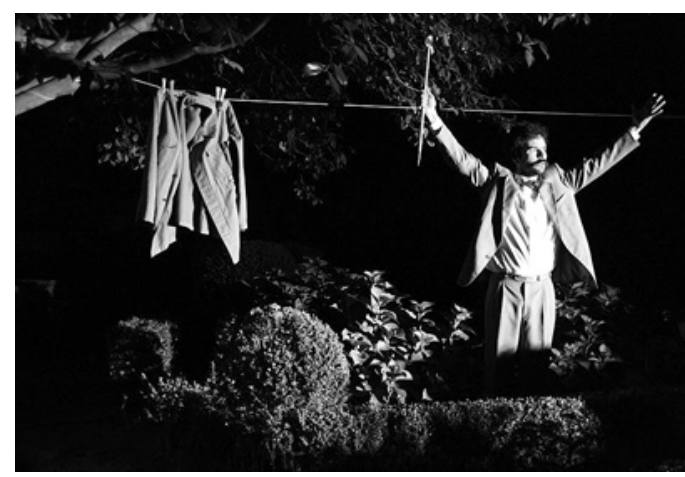

0 teatro não é um filme que se leva para casa, não é um quadro que se vê num museu, não é um livro que se lê na solidão da poltrona. 0 teatro é um desejo comum.

Nestas itinerâncias polifónicas, há ainda lugar para os espectáculos comunitários, onde participam grupos de teatro amador e associações locais, como é o caso da Queima do Judas, dos cinco acontecimentos artísticos que assinalaram a comemoração dos 750 anos do concelho de Monção, ou do muito improvável - mas que, contrariando todas as improbabilidades, conta já com uma segunda edição - FITAVALE (Festival Itinerante de Teatro Amador do Vale do Minho).

São assim as Comédias do Minho: são tudo isto e muito mais, conscientes de que na cidade ou na "discreta vila, perdida no meio da serra, já só pedras e quase a tocar no céu" ${ }^{4}$, o teatro é não só possivel como também necessário.

\section{Referências bibliográficas}

BAILLY, Jean-Christoph (2006), "Un jour mon prince viendra", in STIEGLER/ BAILLY/ GUÉNOUN, Le théâtre, le peuple, la passion, Besançon, Les Solitaires Intempestifs.

GUÉNOUN, Denis (2009), "Que faire du théâtre, Que faire au théâtre", Livraison et délivrance, Paris, Belin.

VITEZ, Antoine (2006), "La Réssurection", Antoine Vitez, Actes Sud-Papiers / Conservatoire d'Art Dramatique, Mettre en Scène.
O fidalgo aprendiz de D. Franscisco Manuel de Mello, enc. João Pedro Vaz, TNDMII e Comédias do Minho, 2011 (Carlos Malvarez), fot. Alipio Padilha.

Casa grande

(Vila Nova de Cerveira), enc. Tânia Almeida Comédias do Minho, 2011 (Rui Mendonça), fot. Celeste Domingues.
${ }^{3}$ Isabel Alves Costa apud Inês Nadais in "Estes actores foram trabalhar para o campo", Público, 03.04.2009.

${ }^{4}$ Tiago Bartolomeu Costa, "De pés na terra e teatro como céu", Público, 24.01.2012. 